\title{
Patient-prosthesis mismatch in new generation trans-catheter heart valves: a propensity score analysis
}

\author{
Alexis Theron ${ }^{1 * \dagger}$, Johan Pinto ${ }^{1 \dagger}$, Dominique Grisoli ${ }^{1}$, Karolina Griffiths ${ }^{2}$, \\ Erwan Salaun ${ }^{3}$, Nicolas Jaussaud ${ }^{1}$, Eléonore Ravis ${ }^{1}$, Marc Lambert ${ }^{3}$, Lyna Messous ${ }^{1}$, \\ Cecile Amanatiou ${ }^{1}$, Thomas Cuisset ${ }^{3}$, Vlad Gariboldi ${ }^{1}$, Roch Giorgi ${ }^{2,4,5,6}$, \\ Gilbert Habib ${ }^{3}$, and Frederic Collart ${ }^{1}$
}

\begin{abstract}
${ }^{1}$ Department of Cardiac Surgery, La Timone Hospital, La Timone Hospital 264, rue saint Pierre 13005 Marseille, France; ${ }^{2}$ APHM, Hôpital de la Timone, Service Biostatistique et Technologies de l'Information et de la Communication, Marseille, France; ${ }^{3}$ Department of Cardiology, La Timone Hospital, Marseille, France; ${ }^{4}$ Aix-Marseille Université, UMR_S 912 (SESSTIM), IRD, 13385 Marseille, France; INSERM, UMR_S 912 (SESSTIM), 13385 Marseille, France; and ${ }^{6}$ Aix Marseille Univ, INSERM, IRD, SESSTIM, Sciences Economiques \& Sociales de la Santé \& Traitement de l'Information Médicale, Marseille, France
\end{abstract}

Received 15 September 2016; editorial decision 20 January 2017; accepted 24 January 2017; online publish-ahead-of-print 27 February 2017

Aims

When compared with the former Sapien XT (XT-THV), the Sapien 3 trans-catheter heart valve (S3-THV) embeds an outer annular sealing cuff to prevent para-valvular regurgitation (PVR). The consequences of this new feature on valve haemodynamics have never been evaluated. We aimed to compare both types of prostheses regarding patient-prosthesis mismatch (PPM).

Methods Patients who underwent a TAVR for aortic stenosis were retrospectively included. Regression adjustment for the and results propensity score was used to compare $50 \mathrm{XT}$-THV patients with $71 \mathrm{~S} 3-\mathrm{THV}$. At the 1-month follow-up, the mean indexed effective orifice area (iEOA) was $1.12 \pm 0.34 \mathrm{~cm}^{2} / \mathrm{m}^{2}$ with $X \mathrm{~T}-\mathrm{THV}$ and $0.96 \pm 0.27 \mathrm{~cm}^{2} / \mathrm{m}^{2}$ with S3-THV. The mean gradient was $11 \pm 5 \mathrm{mmHg}$ and $13 \pm 5 \mathrm{mmHg}$, respectively. Nine patients had moderate PPM, and two exhibited severe PPM with XT-THV. Nineteen patients had moderate PPM, and seven demonstrated severe PPM with S3-THV. There was a five-fold increased risk of PPM with S3-THV (OR=4.98; [1.38-20.94], $P=0.019)$. S3THV decreased the iEOA by $0.21 \mathrm{~cm}^{2} / \mathrm{m}^{2}$ [-0.21; $(-0.38$ to -0.05$\left.) ; P=0.012\right]$ and increased the mean gradient by $4.95 \mathrm{mmHg}$ [4.95; (2.27-7.64); $P<0.001$ ]. The risk of PPM was increased 15.24-fold with $23 \mathrm{~mm}$ S3-THV [15.24; (2.92-101.52); $P=0.002]$ in comparison with the $23 \mathrm{~mm}$ XT-THV. PVR were reduced by $98 \%$ with S3-THV.

Conclusion There is an increased risk of PPM with $23 \mathrm{~mm}$ S3-THV in comparison with $23 \mathrm{~mm}$ XT-THV. This may be attributable to the additional sub-annular cuff that avoids the risk of PVR. Regarding the increased vulnerability of younger patients to PPM, we provide essential information on the extension of TAVR indication to the younger population.

\section{Introduction}

Trans-catheter aortic valve replacement (TAVR) has become a reliable treatment alternative to surgery for aortic stenosis in patients who are inoperable or at a high surgical risk. ${ }^{1}$ Recently, the randomized PARTNER II trial showed similar all-cause death and disabling stroke outcomes of both techniques in intermediate-risk patients, thus widening the TAVR indication to lower-risk patients. ${ }^{2}$ However, the extension of the indications requires a reduction of several prevalent complications, such as para-valvular regurgitation (PVR), which is associated with a poorer prognosis. ${ }^{3}$

Recently, the new expandable Sapien 3 trans-catheter heart valve (S3-THV) has replaced the previous generation of Sapien XT transcatheter heart valve (XT-THV), which was associated with a high

\footnotetext{
* Corresponding author. Tel: +33 4913857 17; Fax: +33491384926. E-mail: alexis.theron@ap-hm.fr

† These authors contributed equally to this work.

Published on behalf of the European Society of Cardiology. All rights reserved. @ The Author 2017. For permissions, please email: journals.permissions@oup.com.
} 
prevalence of PVR. S3-THV provides new features, such as an outer annular sealing polyethylene terephthalate skirt that functions as a blood-soaked sponge and limits the risk of PVR. ${ }^{4}$ However, by bulging into the annular space, this material could lead to turbulence during ventricular ejection and can potentially increase the transprosthetic gradient (see Supplementary data online, Appendix S1). This could expose patients to an underlying risk of patient-prosthesis mismatch (PPM) that occurs when the effective orifice area (EOA) of a normally functioning prosthetic valve is too small in relation to patient body size. ${ }^{5}$ The results from several clinical studies have demonstrated the negative effect of PPM on both functional recovery and life expectancy, emphasizing the need for PPM prevention. ${ }^{6}$

Recently, some authors have suggested the preference of TAVR to surgical valves in patients with a high risk of PPM due to improved haemodynamic performance. ${ }^{7}$

Even though preliminary prospective studies have shown a dramatic reduction of PVR with S3-THV compared with XT -THV, none of these studies have evaluated the haemodynamic effects of the new skirt on post-operative gradients. ${ }^{8}$

In this context, the aim of our study was to retrospectively compare the occurrence of moderate and severe PPM among patients with severe aortic stenosis implanted with S3-THV and XT-THV.

\section{Methods}

\section{Study population}

This retrospective single-centre study was performed from November 2013-15 at La Timone Hospital, Marseille, France. We included 71 consecutive patients with severe aortic stenosis who underwent TAVR with S3-THV (Edwards Lifesciences LLC, Irvine, CA, USA) and 50 consecutive patients who underwent a SAPIEN $X T$ trans-catheter heart valve implantation (XT-THV) (Edwards Lifesciences LLC, Irvine, CA, USA) after heart team endorsement. International review board approval was obtained. Patients who denied authorization for anonymous publication of their clinical data for research purposes were excluded.

\section{Procedure}

Depending on the presence of suitable access sites assessed by the CTscan, TAVR was performed using the transfemoral, transapical, transsubclavian or transaortic approach. The size of the prosthesis was endorsed by the heart team, mainly according to the CT scanned aortic annulus size. ${ }^{9}$ General anaesthesia was performed in all patients. Fluoroscopic guidance guided prosthesis positioning and deployment. Valve implantation was performed under rapid ventricular pacing. Prosthesis position and function were evaluated with angiography, aortic index measurement, and trans-oesophageal echocardiography. More than moderate aortic regurgitation was treated by post-dilatation or second valve implantation.

\section{Data collection and follow-up assessments}

Assessments, including physical examination, NYHA classification, 12 leads electrocardiography and TTE were performed at baseline and at the one-month follow-up. The main exploratory outcome was the occurrence of PPM at 1-month post-TAVR implantation. Secondary exploratory outcomes include the occurrence of PVR, clinical improvement according to NYHA class, in hospital mortality, cardiac tamponade, myocardial infarction, stroke, major bleeding, vascular complication and pacemaker implantation. All outcomes were defined according to the Valve
Aortic Research Consortium-2 definitions. ${ }^{10}$ The rate of oversizing (\%) was calculated using the following formula: \%oversizing $=[T H V$ nominal area/Multi-slice computed tomography (MSCT) annular -1] $\times 100$.

TTE was performed in a Core laboratory by experienced cardiologists. The EOA was calculated according to the continuity equation. The indexed EOA (iEOA) was calculated as the EOA divided by the Body Surface Area. After TAVR implantation, the iEOA was estimated using the Left Ventricular Outflow Tract (LVOT) diameter and velocity measured immediately proximal to the stent, as previously recommended. ${ }^{11}$ Moderate PPM was defined by an iEOA $\leq 0.85 \mathrm{~cm}^{2} / \mathrm{m}^{2}$, and severe PPM was defined by an iEAO $<0.65 \mathrm{~cm}^{2} / \mathrm{m}^{26}$. An integrative semi-quantitative approach was used to assess the severity of central and PVR. The left ventricular mass regression ratio was calculated as (1-month follow-up LV mass - Baseline LV mass/Baseline LV mass), similar to functional amelioration (1-month follow-up NYHA—Baseline NYHA/Baseline NYHA).

\section{Statistical analysis}

The continuous variables were described by mean, SD, minimum and maximum values. The categorical variables were described by size and percentage. For the baseline analysis, categorical variables were compared with the type of prosthesis using $\chi^{2}$ or Fisher's exact test, according to the conditions of application. The non-parametric Wilcoxon signedrank test was used for continuous variables (paired if comparing baseline to follow-up characteristics).

A large number of preoperative baseline characteristics varied between the two groups. In order to adjust for these between group differences, propensity scores, which estimate the probability of treatment (prosthesis) assignment was calculated with the use of logistic regression. The following baseline and preoperative (unless otherwise stated) covariates were used in a logistic regression model. Regression adjustment for the propensity score was then used (see Supplementary data online, Appendix S2). The comparison of XT-THV to S3-THV was performed in the overall population and in subgroup analysis by prosthesis size, only the 23- and 26-mm groups were included (both the smallest and largest size groups had small sample sizes).

Sensitivity analyses included an alternative method for propensity score modelling, using inverse probability treatment weighting (IPTW). The final propensity score models were evaluated by comparing the covariate distribution and propensity score between groups before and after IPTW. These weights were used in the subsequent logistic regression analysis. The average treatment effect was calculated to answer the question if the valve XT THV results in better outcomes for patients drawn from the population as a whole. The results were considered statistically significant with a $P$ value of $P \leq 0.05$. Statistical analysis was performed using the software programme $R$ (version 3.1.0).

\section{Results}

\section{Baseline and echo characteristics}

In total, 121 patients (mean age $=82.4 \pm 6.5$ years; $60 \%$ females) were enrolled: 50 patients to the XT-THV subgroup, and 71 patients to the S3-THV subgroup. Eighty-five patients (70\%) had hypertension. The mean BSA was $1.70 \pm 0.22 \mathrm{~m}^{2}$. Seventy patients (58\%) were in NYHA III and IV, and 49 patients (40.5\%) had recently presented with congestive heart failure. The mean LVEF was $56 \pm 13 \%$. The mean aortic annulus diameter was $20.9 \pm 1.95 \mathrm{~mm}$. All patients had severe AS, with a mean iEOA of $0.41 \pm 0.13 \mathrm{~cm}^{2} / \mathrm{m}^{2}$ and a mean trans-aortic gradient of $51 \pm 16 \mathrm{mmHg}$. Female gender was significantly more frequent in the XT-THV subgroup (78 and 48\%, $P<$ 
Table I Baseline characteristics

\begin{tabular}{|c|c|c|c|c|}
\hline & $\begin{array}{l}\text { All } \\
n=121\end{array}$ & $\begin{array}{l}\text { XT-THV } \\
n=50\end{array}$ & $\begin{array}{l}\text { S3-THV } \\
n=71\end{array}$ & $p$ \\
\hline Age, years & $82.4 \pm 6.5$ & $83.3 \pm 6.6$ & $81.7 \pm 6.4$ & 0.13 \\
\hline Females (\%) & $73(60 \%)$ & $39(78 \%)$ & $34(48 \%)$ & $<0.001$ \\
\hline $\mathrm{BSA}, \mathrm{m}^{2}$ & $1.70 \pm 0.22$ & $1.63 \pm 0.17$ & $1.75 \pm 0.24$ & 0.04 \\
\hline Mellitus Diabetes & 39 (32\%) & $19(38 \%)$ & $20(28 \%)$ & 0.25 \\
\hline Hypertension & $85(70 \%)$ & $39(78 \%)$ & $46(65 \%)$ & 0.11 \\
\hline Smoke & $10(8 \%)$ & $3(6 \%)$ & $7(10 \%)$ & 0.52 \\
\hline Dyslipidaemia & $46(38 \%)$ & $24(48 \%)$ & $22(31 \%)$ & 0.05 \\
\hline Coronary artery disease & $56(46 \%)$ & $26(52 \%)$ & $30(42 \%)$ & 0.29 \\
\hline Renal insufficiency & $23(19 \%)$ & $13(26 \%)$ & $10(14 \%)$ & 0.09 \\
\hline $\begin{array}{l}\text { Chronic pulmonary } \\
\text { disease }\end{array}$ & $14(12 \%)$ & $4(8 \%)$ & $10(14 \%)$ & 0.3 \\
\hline Cerebrovascular disease & $5(4 \%)$ & $1(2 \%)$ & $4(6 \%)$ & 0.4 \\
\hline Porcelain aorta & $3(2 \%)$ & $1(2 \%)$ & $2(3 \%)$ & 1 \\
\hline Atrial fibrillation & $31(26 \%)$ & $10(20 \%)$ & $21(30 \%)$ & 0.23 \\
\hline NYHA & & & & 0.61 \\
\hline 1 & $10(8 \%)$ & $4(8 \%)$ & $6(8 \%)$ & \\
\hline ॥ & $41(34 \%)$ & $15(30 \%)$ & $26(37 \%)$ & \\
\hline III & $58(48 \%)$ & $24(48 \%)$ & $34(48 \%)$ & \\
\hline IV & $12(10 \%)$ & $7(14 \%)$ & $5(7 \%)$ & \\
\hline Recent CHF & 49 (40.5\%) & $29(58 \%)$ & $20(28 \%)$ & 0.001 \\
\hline Haemoglobin (g/L) & $119 \pm 17$ & $116 \pm 17$ & $121 \pm 17$ & 0.04 \\
\hline $\mathrm{BNP}(\mathrm{pg} / \mathrm{mL})$ & $417 \pm 364$ & $454 \pm 358$ & $390 \pm 369$ & 0.11 \\
\hline Creatinine $(\mu \mathrm{mol} / \mathrm{L})$ & $129 \pm 126$ & $131 \pm 170$ & $128 \pm 82$ & 0.26 \\
\hline
\end{tabular}

BSA, body surface area; $\mathrm{CHF}$, congestive heart failure.

0.001), which is consistent with a lower BSA $\left(1.63 \pm 0.17 \mathrm{~m}^{2}\right.$ vs. $\left.1.75 \pm 0.24 \mathrm{~m}^{2}, P=0.04\right)$, lower haemoglobin rate $(116 \pm 17$ and $121 \pm 17 \mathrm{~g} / \mathrm{dL}, P=0.04)$, and lower aortic annulus diameter on TTE $(20.2 \pm 1.7 \mathrm{~mm}$ vs. $21.5 \pm 1.95, P<0.001)$ (Tables 1 and 2$)$.

\section{Procedural characteristics}

Among the XT-THV patients, three patients had a $20 \mathrm{~mm}$ (6\%), 24 had a $23 \mathrm{~mm}$ (48\%), 21 had a $26 \mathrm{~mm}(42 \%)$, and two had a $29 \mathrm{~mm}$ (4\%). Among the S3-THV patients, 34 had a $23 \mathrm{~mm}$ (48\%), $30 \mathrm{had}$ a $26 \mathrm{~mm}(42 \%)$, and six had a $29 \mathrm{~mm}(10 \%)$. Aortic annuli were larger with $23 \mathrm{~mm}$ and $26 \mathrm{~mm}$ S3-THV, shown by larger MSCT aortic annulus area $(P<0.001)$ and lower prosthesis to annulus oversizing. Figure $1 A$ and $B$. There were no differences between the groups regarding procedural events, such as vascular complications or pacemaker implantation.

\section{Clinical follow-up}

At 1-month follow-up, five deaths (4\%) had occurred, all in the XTTHV subgroup. Seventy-three patients $(63 \%)$ clinically improved $(P<$ 0.001 ), with a mean improvement of $21 \pm 4.7 \%$. No difference was observed between the two prostheses in terms of functional improvement in the NYHA class ( 25 vs. $15 \%, P=0.6$ ). Propensity score analysis demonstrated that the S3-THV did not affect functional improvement when compared with the XT-THV [Coefficient $=0.09$, $(-0.17-0.35), P=0.49]$.

\section{Haemodynamic follow-up}

The overall echocardiographic data and data according to valve type at 1-month follow-up are provided in Table 3. The mean gradient decreased significantly from baseline to 1-month follow-up (51.0 \pm 16.0 vs. $12.0 \pm 5.0 \mathrm{mmHg}, P<0.001)$, and LVEF slightly increased (60 \pm 12 vs. $56 \pm 13 \%, P<0.001)$. At 1-month follow-up, the mean EOA was $1.71 \pm 0.52 \mathrm{~cm}^{2} / \mathrm{m}^{2}$, which corresponded to a mean iEOA of $1.2 \pm 0.31 \mathrm{~cm}^{2} / \mathrm{m}^{2}$. Thirty-seven patients (30.5\%) had PPM, of which 28 (76\%) had moderate and nine (15\%) had severe PPM.

Among the 28 patients with moderate PPM, nine patients (32.1\%) received a XT-THV (one with $20 \mathrm{~mm}$, four with $23 \mathrm{~mm}$, and four with $26 \mathrm{~mm}$ XT-THV), and 19 patients (67.9\%) had S3-THV (12 with $23 \mathrm{~mm}, 5$ with $26 \mathrm{~mm}$, and 2 with $29 \mathrm{~mm} \mathrm{S3-THV).} \mathrm{Among} \mathrm{the} \mathrm{nine}$ patients with severe PPM, two (22.2\%) had a XT-THV (20 mm XTTHV in all), and seven (77.8\%) had a S3-THV (six with $23 \mathrm{~mm}$ and one with $26 \mathrm{~mm} \mathrm{S3-THV)} \mathrm{Table} 4$ (see Supplementary data online, Appendix S3A and S3B).

No difference in BSA was observed between patients with and without PPM (BSA = $1.73 \pm 0.18$ vs. $1.67 \pm 0.19 \mathrm{~m}^{2}, P=0.12$ ). The mean trans-prosthetic gradient was significantly higher in patients with PPM vs. no PPM (15.2 \pm 5.3 vs. $11.2 \pm 4.5 \mathrm{mmHg}, P<0.001)$ (see Supplementary data online, Appendix S2).

S3-THV was significantly associated with lower iEOA (0.96 \pm 0.27 and $\left.1.12 \pm 0.34 \mathrm{~cm}^{2} / \mathrm{m}^{2}, P<0.01\right)$ and higher mean trans-aortic gradient $(13 \pm 5$ vs. $11 \pm 5 \mathrm{mmHg}, P=0.002)$ than the XT-THV group in univariate analysis.

Using a linear regression adjustment of the propensity score, S3THV decreased the iEOA by around $-0.21 \mathrm{~cm}^{2} / \mathrm{m}^{2}$ [Coefficient $=-0.21,(-0.38$ to -0.05$), P=0.013$ ] and increased the mean trans-prosthetic gradient by $+4.95 \mathrm{mmHg}$ [Coefficient $=4.95$, (2.27-7.64), $P<0.001$ ] compared with XT-THV. Figure 2 Sensitivity analysis using a linear regression with IPTW of the propensity score had similar results for both decreasing the iEOA $[-0.11 \quad(-0.21$ to -0.02$), P=0.019]$ and increasing the mean trans-prosthetic gradient [4.38, (2.88-5.88), $P<0.001]$. Consistent with these findings, S3THV implantation was significantly associated with a higher risk of PPM $[O R=4.98,(1.38-20.94), P=0.019]$ using logistic regression adjustment of the propensity score. Figure $3 A$ Sensitivity analysis also identified a higher risk of PPM with S3-THV implantation in comparison with XT-THV [OR = 7.24, (3.62-15.38), $P \leq 0.00001]$

The same modalities of regression were used in the subgroup analysis with regard to prosthesis size. Among patients with a size of $23 \mathrm{~mm}, \mathrm{~S} 3-\mathrm{THV}$ decreased the iEOA by around $0.26 \mathrm{~cm}^{2} / \mathrm{m}^{2}$ [coefficient $=-0.26,(-0.44$ to -0.08$), P=0.005$ ] and increased the mean trans-prosthetic gradient by around $5.63 \mathrm{mmHg}$ [coefficient $=$ 5.63, (2.8-8.45), $P<0.001$ ] compared with the $23 \mathrm{~mm}$ XT -THV. There was a 15-fold increased risk of PPM with $23 \mathrm{~mm}$ S3-THV vs. $23 \mathrm{~mm}$ XT-THV [OR = 15.24, (2.92-101.52), $P=0.002$ ]. Figure 3B Sensitivity analysis supports these results and also identified a lower iEOA [-0.16, (-0.28 to-0.04), $P=0.008)$, a higher mean transprosthetic gradient [5.91, (4.11-7.71), $P<0.00001]$ and a 25-fold increased risk of PPM [25.95 (9.43-86.90), $P<0.00001]$ in the $23 \mathrm{~mm}$ S3-THV compared with the $23 \mathrm{~mm} \times \mathrm{T}-\mathrm{THV}$

Among patients with $26 \mathrm{~mm}-\mathrm{THV}$, no significant difference was found concerning the EOAi [coefficient $=-0.13,(-0.31$ to 0.06$), P=$ 0.18 ] or PPM risk [OR $=1.77,(0.312-11.27), P=0.068]$. Figure $3 C$ 
Table 2 Echocardiography data at baseline

\begin{tabular}{|c|c|c|c|c|}
\hline & $\begin{array}{l}\text { All } \\
n=121\end{array}$ & $\begin{array}{l}\text { XT-THV } \\
n=50\end{array}$ & $\begin{array}{l}\text { S3-THV } \\
n=71\end{array}$ & $P$ \\
\hline LVEF (\%) & $56 \pm 13$ & $55 \pm 13$ & $56 \pm 13$ & 0.61 \\
\hline LVEF < 50\% (\%) & $31(25 \%)$ & $12(24 \%)$ & 19 (26.7\%) & 0.4 \\
\hline LV septum diameter (mm) & $14.8 \pm 2.4$ & $14.5 \pm 2.4$ & $15 \pm 2.4$ & 0.46 \\
\hline LV diastolic diameter (mm) & $46.8 \pm 6.7$ & $48.3 \pm 7.2$ & $45.5 \pm 6$ & 0.16 \\
\hline LV systolic diameter (mm) & $32 \pm 6.9$ & $33.6 \pm 7$ & $31 \pm 6.7$ & 0.32 \\
\hline LV mass $\left(g / m^{2}\right)$ & $178 \pm 52$ & $190 \pm 51$ & $168 \pm 51$ & 0.08 \\
\hline Aortic annulus diameter (mm) & $20.9 \pm 1.95$ & $20.2 \pm 1.7$ & $21.5 \pm 1.95$ & $<0.001$ \\
\hline $\mathrm{EOA}\left(\mathrm{cm}^{2}\right)$ & $0.69 \pm 0.22$ & $0.65 \pm 0.19$ & $0.71 \pm 0.23$ & 0.057 \\
\hline $\mathrm{iEOA}\left(\mathrm{cm}^{2} / \mathrm{m}^{2}\right)$ & $0.41 \pm 0.13$ & $0.4 \pm 0.12$ & $0.42 \pm 0.14$ & 0.44 \\
\hline Mean trans-aortic gradient $(\mathrm{mmHg})$ & $51 \pm 16$ & $52 \pm 16$ & $51 \pm 16$ & 0.66 \\
\hline Aortic regurgitation & $63(52 \%)$ & $35(70 \%)$ & $28(39 \%)$ & $<0.001$ \\
\hline Aortic regurgitation grade & & & & 0.001 \\
\hline Trivial & $40(63 \%)$ & $23(66 \%)$ & $17(61 \%)$ & \\
\hline Mild & $13(21 \%)$ & $5(14 \%)$ & $8(29 \%)$ & \\
\hline Moderate & $4(6 \%)$ & $4(11 \%)$ & 0 & \\
\hline Severe & $6(4.9 \%)$ & $3(9 \%)$ & $3(10 \%)$ & \\
\hline Mitral regurgitation & $57(47 \%)$ & $33(66 \%)$ & $24(34 \%)$ & $<0.001$ \\
\hline Mitral regurgitation 3-4 & $4(3.3 \%)$ & $1(2 \%)$ & $3(4.2 \%)$ & 0.46 \\
\hline Systolic pressure of pulmonary artery & $42 \pm 14$ & $44 \pm 14$ & $39 \pm 15$ & 0.08 \\
\hline
\end{tabular}

LVEF, left ventricular ejection fraction; LV, left ventricle; EOA, effective orifice area; iEOA, indexed effective orifice area.

However, the $26 \mathrm{~mm}$ S3-THV increased the mean trans-prosthetic gradient by $4.54 \mathrm{mmHg}$ [coefficient $=4.54,(1.64-7.44), P=0.002$ ] compared with the $26 \mathrm{~mm}$ XT-THV.

Sixty-one patients (53\%) had a PVR at the 1-month follow-up, including 37 patients (82\%) in the XT-THV group and 24 patients (34\%) in the S3-THV. Among these patients, 47 (77\%) had trivial PVR, twelve (20\%) had mild/moderate PVR and 2 (3\%) had severe PVR. Among the XT-THV group, 26 patients (70\%) had trivial PVR, 9 (24\%) had mild/moderate PVR and 2 (6\%) had severe PVR. Neither moderate nor severe PVR were observed in the S3-THV group, whereas 21 (88\%) had trivial PVR and 3 (12\%) had mild PVR.

Using a logistic regression adjustment of the propensity score, the odds of a para-prosthetic leak were $98 \%$ reduced with S3-THV compared with XT-THV [OR $=0.02,(0.002-0.095), P<0.001]$. Figure 4 Sensitivity analysis results for PVR were consistent $[O R=0.03(0.01-$ $0.06), P<0.00001$ ] with much narrower confidence intervals.

\section{Discussion}

The aim of this study was to compare the occurrence of moderate and severe PPM with the new balloon-expandable S3-THV vs. the preceding XT-THV generation in TAVI for severe AS. The main findings were (i) a higher risk of PPM for S3-THV, (ii) a 15-fold increased risk of PPM with the smallest size of S3-THV prosthesis in comparison with the same size XT-THV prosthesis, and (iii) a similar degree of left ventricular mass regression and NYHA functional improvement with both valves.

The clinical effect of PPM after surgical aortic valve replacement (SAVR) has been a matter of controversy since the first description by Rahimtoola in $1978 .{ }^{5}$ PPM occurs if the EOA of the implanted bioprosthesis is small relative to the patient body size.

PPM is considered severe when the iEOA is $<0.65 \mathrm{~cm}^{2} / \mathrm{m}^{2}$ and moderate if the iEOA is between 0.65 and $0.85 \mathrm{~cm}^{2} / \mathrm{m}^{2}$. The occurrence of PPM post-SAVR is well recognized and ranges from 20 to $70 \%$ for moderate PPM and from 2 to $10 \%$ for severe PPM. ${ }^{12}$ The adverse effects of PPM include functional impairment, reduced LV mass regression and a significant reduction of early and intermediate survival, particularly in severe PPM. ${ }^{13}$ A recent meta-analysis of 34 studies with 27186 patients confirmed a significantly negative effect of PPM on long-term survival, particularly in cases of vulnerability, such as impaired LVEF, severe LV hypertrophy, concomitant mitral regurgitation, and/or paradoxical low flow/low gradient aortic stenosis. ${ }^{14}$

When compared with SAVR, the previous prostheses used for TAVR, such as Edwards Sapien and Sapien-XT, tend to have better haemodynamic performance, thus contributing to a reduction in PPM. $^{15}$ In a randomized comparison of 699 patients from the PARTNER trial A cohort, TAVR was significantly associated with less PPM (46.4 vs. $60.0 \%, P<0.001)$ and severe PPM (19.7 vs. $28.1 \%, P<$ 0.001) compared with SAVR. ${ }^{7}$ This study was also the first to identify an important relationship between PPM after TAVR implantation and 2-year mortality, but this relationship was found only in the TAVR nonrandomized continued access arm. The difference in severe PPM was particularly important in patients with small aortic annuli $(<20 \mathrm{~mm})$, assuming that the thinner stent frame and absence of a sewing ring in the annular space provide less blood flow obstruction. However, this study was based on the former generation of SAPIEN/ SAPIEN XT-THV, and none of these haemodynamic results could be extended to the new S3-THV generation, which embedded supplementary annular space material. 


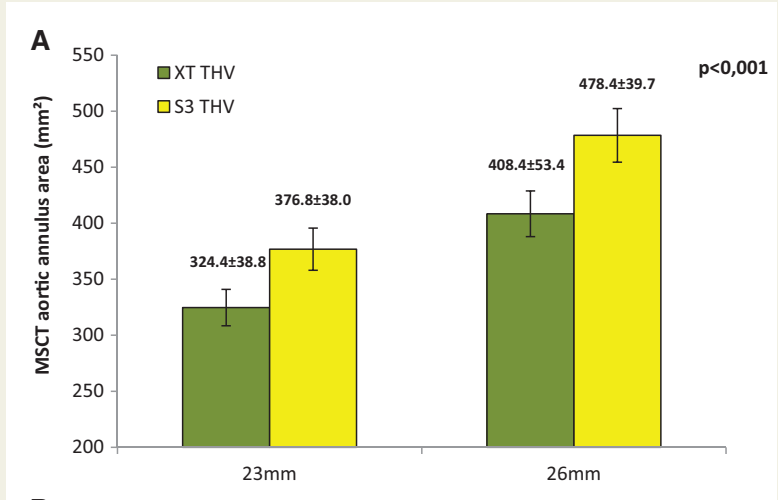

B

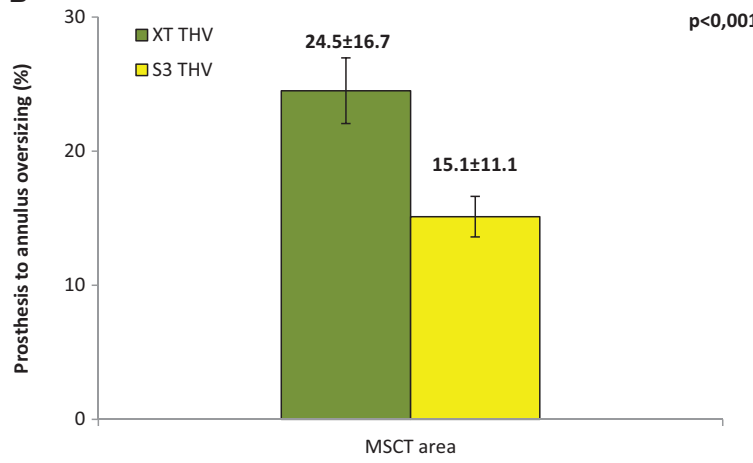

Figure I MSCT aortic annulus area for XT-THV and S3-THV according prosthesis size (A). Prosthesis to annulus oversizing (\%) for both prosthesis size. Data are presented as mean \pm SD.

Several studies have compared the two types of XT-THV and S3THV by focusing on PVR occurrence but, to the best of our knowledge, our study is the first to compare the occurrence of PPM in both prosthesis groups. ${ }^{4,16}$ Our main finding was that S3-THV was associated with a higher risk of moderate and severe PPM than XTTHV implantation. We showed that the iEOA was significantly lower $\left(1.12 \pm 0.34\right.$ vs. $\left.0.96 \pm 0.27 \mathrm{~cm}^{2 /} \mathrm{m}^{2}, P=0.009\right)$ and the mean transprosthetic gradient was significantly higher $(11.0 \pm 5.5$ and $13.5 \pm$ $4.7 \mathrm{mmHg}, P=0.002$ ) in S3-THV. Strikingly, S3-THV significantly decreased the iEOA by $-0.21 \mathrm{~cm}^{2} / \mathrm{m}^{2}$ and increased the mean transprosthetic gradient by $+4.95 \mathrm{mmHg}$ compared with the XT-THV. Consequently, the risk of PPM increased nearly 5-fold for S3-THV implantation. More specifically, the smallest aortic annulus patients who received a $23 \mathrm{~mm}$ S3-THV prosthesis demonstrated a 15-fold increased risk of PPM compared with $23 \mathrm{~mm}$ XT-THV whereas aortic annuli were significantly lower with XT-THV (324 \pm 38.8 vs. 376.8 $\left.\pm 38 \mathrm{~mm}^{2}, P<0.001\right)$. Binder et al. previously showed a trend to a lower EOA and higher trans-prosthetic gradient in S3-THV compared with the XT-THV group $\left(1.43 \pm 0.4\right.$ vs. $1.51 \pm 0.43 \mathrm{~cm}^{2}, P=$ 0.38 and $11.65 \pm 5.98$ vs. $9.96 \pm 4.77, P=0.08$ for $23 \mathrm{~mm}$ prosthesis), but the absence of EOA indexation to BSA did not permit the reporting of the incidence of PPM in this cohort. ${ }^{4}$

The increase in both the risk and severity of high trans-prosthetic gradients and PPM could be explained by the outer sealing cuff, which is embedded in the new S3-THV. This new feature bulges into the annular space after deployment to fill up irregularities. In concordance with previous studies, the reduction in rate and severity of PVR was confirmed in our study (34 and 82\%, $P<0.001) .{ }^{17}$ However, although this novelty achieved a lower rate of PVR, the presence of a supple mentary material occupying the annular space could have favoured a systolic blood obstruction and detrimental haemodynamic performance, particularly in the case of a small aortic annulus.

A reduction in aortic annulus oversizing for the S3-THV compared with XT-THV could also explain the increase observed in postoperative gradients. Oversizing was often used with XT-THV to prevent PVR and valve embolization. However, the S3-THV requires less oversizing than the XT-THV because it has a skirt to prevent PVR. In our study, native aortic annuli were smallest for patients implanted with XT-THV than S3-THV. We reported a 38\% reduction in annular aortic area oversizing for the S3-THV compared with XT$\mathrm{THV}$, similar to the results of Nijhoff et al. ${ }^{16} \mathrm{We}$ could assumed that if similar sizing algorithm has been applied for S3 vs. XT, this would negatively impact the haemodynamics of the S3-THV relative to the XT-THV. In fact, the SAPIEN 3 is a device that shortens substantially when it is deployed. Oversizing may result in under-deployed and 'under-shortened' valve stent, which may in turn lead to suboptimal haemodynamic. Then, we compared mean iEOA in patients with 23 $\mathrm{mm}$ S3-THV without and with oversizing to show what would have happened if the former algorithm has been applied. Surprisingly, indexed EOA and mean trans-prosthetic gradients were similar in both group $\left(0.85 \pm 0.32 \mathrm{~cm}^{2} / \mathrm{m}^{2}\right.$ vs. $0.89 \pm 0.21 \mathrm{~cm}^{2} / \mathrm{m}^{2}, P=0.59$ and $13.8 \pm 5.3 \mathrm{mmHg}$ vs. $16.55 \pm 4.9 \mathrm{mmHg}, P=0.15)$ but some caution should be taken with regard to the limited size of our study. Similarly, Nijhoff et al. reported that oversizing was not associated with higher trans-prosthetic gradients or reduced EOA in their study. ${ }^{18}$ Finally, the rate of balloon post-dilatation was similar in both subgroups and does not explain the haemodynamic difference.

The relative $L V$ mass reduction was comparable and incomplete with $\mathrm{XT}-\mathrm{THV}$ and S3-THV, thus suggesting a persistence of $\mathrm{LV}$ afterload in both subgroups. One explanatory hypothesis is that S3-THV had the highest risk of PPM, whereas XT-THV experienced the highest occurrence of PVR. ${ }^{3}$ Both haemodynamic sequelae contribute to limiting LV hypertrophy regression, and further investigations are mandatory to evaluate the respective strength of each parameter on myocardial recovery and prognosis. ${ }^{19}$ Additionally, baseline aortic regurgitation was significantly more prevalent in the XT-THV group and could have prolonged the duration and limit the completeness of LV mass regression. ${ }^{20}$ Finally, the follow-up period was short, and the implanted patients were older and mainly had hypertension. This attribute may have compromised optimal LV remodelling.

Taken together, our results suggest that S3-THV reduces the risk of PVR at the expense of having a higher risk of PPM. These findings have to be considered in an era of the extension of the indications to younger patients with less comorbidity, who are more vulnerable to PPM than the elderly.

\section{Strengths and limitations}

The main limitations are the retrospective, single-centre, nonrandomized design of the study. However, the use of propensity score analysis is a well-established approach in observational research to address differences between treatments and to reduce bias 
Table 3 Echocardiographic data at 1-month follow-up

\begin{tabular}{|c|c|c|c|c|}
\hline & $\begin{array}{l}\text { All } \\
n=121\end{array}$ & $\begin{array}{l}\text { XT-THV } \\
n=50\end{array}$ & $\begin{array}{l}\text { S3-THV } \\
n=71\end{array}$ & $\mathbf{p}$ \\
\hline LVEF (\%) & $60.2 \pm 12.3$ & $58.2 \pm 11.5$ & $61.5 \pm 12.7$ & 0.14 \\
\hline LV septum diameter $(\mathrm{mm})$ & $13.8 \pm 1.95$ & $13.3 \pm 1.9$ & $14.1 \pm 1.9$ & 0.08 \\
\hline LV Diastolic diameter (mm) & $44.5 \pm 6.9$ & $44.8 \pm 6.9$ & $44.3 \pm 6.9$ & 0.77 \\
\hline LV Systolic diameter (mm) & $32.3 \pm 6.7$ & $32.5 \pm 6.3$ & $32.2 \pm 7$ & 0.88 \\
\hline LV mass $(g / m 2)$ & $140.2 \pm 39.5$ & $139.2 \pm 42$ & $141 \pm 38.1$ & 0.83 \\
\hline Relative LV mass regression & $18 \%$ & $20 \%$ & $17 \%$ & 0.63 \\
\hline Aortic annulus diameter (mm) & $21.1 \pm 1.7$ & $20.7 \pm 1.4$ & $21.4 \pm 1.8$ & 0.03 \\
\hline Systolic Pulmonary artery pressure & $40.4 \pm 13.4$ & $40.3 \pm 11.9$ & $40.5 \pm 14.5$ & 0.67 \\
\hline $\mathrm{EOA}\left(\mathrm{cm}^{2}\right)$ & $1.71 \pm 0.52$ & $1.78 \pm 0.61$ & $1.66 \pm 0.45$ & 0.19 \\
\hline $\mathrm{iEOA}\left(\mathrm{cm}^{2} / \mathrm{m}^{2}\right)$ & $1.02 \pm 0.31$ & $1.12 \pm 0.34$ & $0.96 \pm 0.27$ & 0.009 \\
\hline Mean trans-aortic gradient $(\mathrm{mmHg})$ & $12.5 \pm 5.1$ & $11 \pm 5.5$ & $13.5 \pm 4.7$ & 0.002 \\
\hline $\mathrm{SVI}\left(\mathrm{mL} / \mathrm{m}^{2}\right)$ & $46.9 \pm 9.7$ & $49.5 \pm 7.7$ & $45.2 \pm 10.5$ & 0.01 \\
\hline Mismatch & $37(32 \%)$ & $11(24 \%)$ & $26(36 \%)$ & 0.17 \\
\hline Mismatch grade & & & & 0.35 \\
\hline Moderate & $28(76 \%)$ & $9(82 \%)$ & $19(73 \%)$ & \\
\hline Severe & $9(24 \%)$ & $2(18 \%)$ & $7(27 \%)$ & \\
\hline Paravalvular aortic regurgitation & $61(53 \%)$ & $37(82 \%)$ & $24(34 \%)$ & $<0.001$ \\
\hline PVR grade & & & & $<0.001$ \\
\hline Trivial & $47(77 \%)$ & $26(70 \%)$ & $21(88 \%)$ & \\
\hline Mild & $12(20 \%)$ & $9(24 \%)$ & $3(12 \%)$ & \\
\hline Moderate & $1(1.5 \%)$ & $1(3 \%)$ & 0 & \\
\hline Severe & $1(1.5 \%)$ & $1(3 \%)$ & 0 & \\
\hline
\end{tabular}

LVEF, left ventricular ejection fraction; LV, left ventricle; EOA, effective orifice area; iEOA, indexed effective orifice area.

Table 4 Haemodynamic comparison of XT-THV vs. S3-THV at 1-month follow-up according to valve size

\begin{tabular}{|c|c|c|c|c|c|c|}
\hline & \multicolumn{3}{|c|}{ XT THV SIZE } & \multicolumn{3}{|c|}{ S3 THV SIZE } \\
\hline & XT $23 \mathrm{~mm}$ & XT $26 \mathrm{~mm}$ & XT $29 \mathrm{~mm}$ & S3 $23 \mathrm{~mm}$ & S3 $26 \mathrm{~mm}$ & S3 $29 \mathrm{~mm}$ \\
\hline EOA & $1.76 \pm 0.47$ & $1.93 \pm 0.49$ & 3.4 & $1.45 \pm 0.4$ & $1.87 \pm 0.14$ & $1.77 \pm 0.46$ \\
\hline ¡EOA & $1.12 \pm 0.3$ & $1.16 \pm 0.3$ & 1.9 & $0.87 \pm 0.25$ & $1.04 \pm 0.25$ & $1.06 \pm 0.32$ \\
\hline Stroke volume index & $51.5 \pm 8$ & $48 \pm 6$ & 43 & $46 \pm 12$ & $46 \pm 9.6$ & $39 \pm 6.4$ \\
\hline Mean gradient & $11 \pm 4$ & $9 \pm 4$ & 12 & $15 \pm 5$ & $12 \pm 3$ & $10 \pm 5$ \\
\hline Mismatch & $4(17 \%)$ & $4(19 \%)$ & 0 & $18(53 \%)$ & $6(20 \%)$ & $2(29 \%)$ \\
\hline Moderate & 4 & 4 & 0 & 12 & 5 & 2 \\
\hline Severe & 0 & 0 & 0 & 6 & 1 & 0 \\
\hline
\end{tabular}

EOA, effective orifice area; iEOA, indexed effective orifice area, three mismatches occurred with XT THV 20 mm: two (66\%) severe and one (33\%) moderate.

due to confounding variables. ${ }^{14}$ We used two transparent methods: regression adjustment and inverse weighting by the propensity score (IPTW). Two other well-described propensity score approaches were not appropriate (matching and stratification) due to differing population distributions of covariates in the two baseline groups and small sample sizes - including empty propensity score strata and lack of good matches. As there can be disadvantages of regression adjustment, we validated our results using IPTW, which reduces bias and is less vulnerable to extrapolation. This method has been previously used in cardiovascular research and is appropriate for not wellbalanced matches and to retain all study data. ${ }^{21}$
The calculation of the 'projected' in vivo indexed EOA is particularly interesting in the clinical decision-making process to avoid the risk of post-operative PPM. The 'projected' in vivo EOA is obtained by dividing the in vivo EOA provided by the manufacturer by the body surface area. ${ }^{6}$ For surgical bioprosthesis, manufacturers provide reliable in vivo EOA data for each prosthesis size based on several echocardiographic studies. For a given size, it is assumed that in vivo EOA could not varied from one patient to another because the diameter of a stented bioprosthesis do not varied from one patient to another and the EOA is independent of flow. 
A
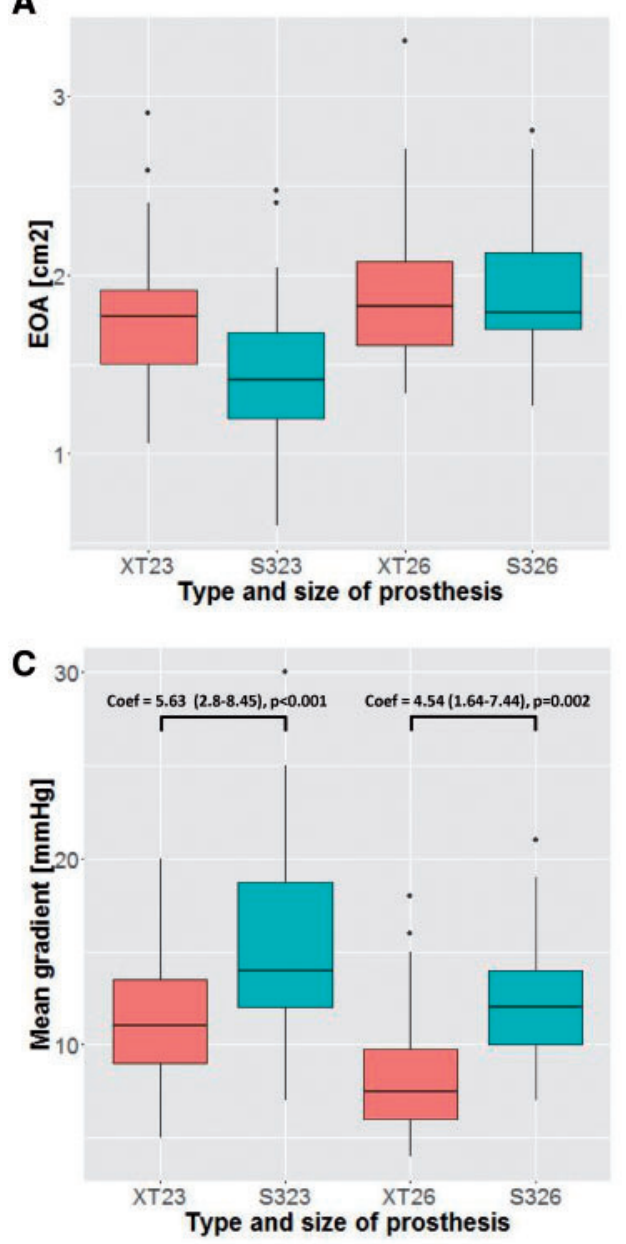

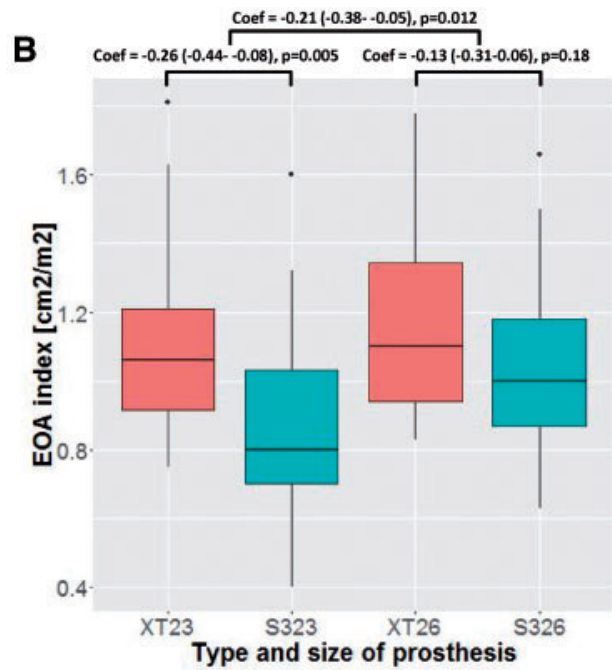

Concerning THV, many pre- or peri-procedural factors varying from one patient to another, such as the degree of stent deployment, the presence and/or the localization of native valve calcification, the height of valve implantation and the ring anatomy could influence directly the estimation of post-operative iEOA. ${ }^{11}$ Consequently, no in vivo $\mathrm{iEOA}$ per size are provided by manufacturer for THV. For all these reasons, we didn't use the 'projected' iEAO to diagnose PPM after THV implantation even if the presently reported values for EOA might present a unique frame of reference with regards to the haemodynamic performance to be expected from these prostheses.

Several errors can occur in this estimation of iEOA, particularly for TAVR prosthesis where LVOT diameter and LVOT VTI assessment were particularly challenging. In this study, all echocardiography was performed in a core laboratory by two experienced cardiologists to limit the risk of intra/inter-observer variability. Another cause of the discrepancies in the iEOA measurement may be the occurrence of a low-flow state [i.e. stroke volume index $(\mathrm{SVI})<35 \mathrm{~mL} / \mathrm{m}^{2}$ ]. In our study, only nine patients demonstrated a post-implantation low-flow state (mean LVEF $=43.6 \pm 8.5 \%$, mean LVOT diameter $=21.5 \pm 2.5$ $\mathrm{mm}$, mean SVI $=28.1 \pm 4.25 \mathrm{~mL} / \mathrm{m}^{2}$, mean $\left.\mathrm{iEOA}=0.82 \mathrm{~cm} / \mathrm{m}^{2}\right)$. These patients belonged exclusively to the S3-THV group, which could suggest some technical difficulties in SVI calculation in this subgroup. However, the LVOT measurements method was the same for both type of prosthesis and LVOT VTI measurement was also standardized by positioning the pulsed-wave Doppler sample volume at $1.0 \mathrm{~cm}$ below the THV insertion. ${ }^{13}$ The main reasons to explain the absence of low-flow state with XT-THV were the higher occurrence of PVR and the lower BSA due to a female predominance. Similarly, the higher occurrence of PVR in the XT-THV group could have increased the mean trans-prosthetic gradient.

Finally, iEOA may also be underestimated if the ascending aorta diameter is $<30 \mathrm{~mm}$ because of the risk of pressure recovery phenomenon. ${ }^{22}$ Unfortunately, too many data were missing to provide reliable data concerning the estimation of the energy loss index. 
A 60

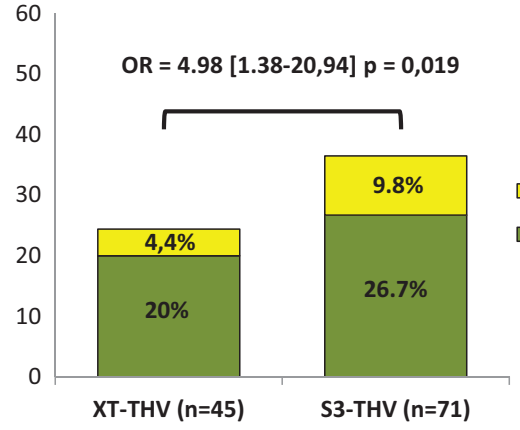

$\mathbf{C}_{40}$

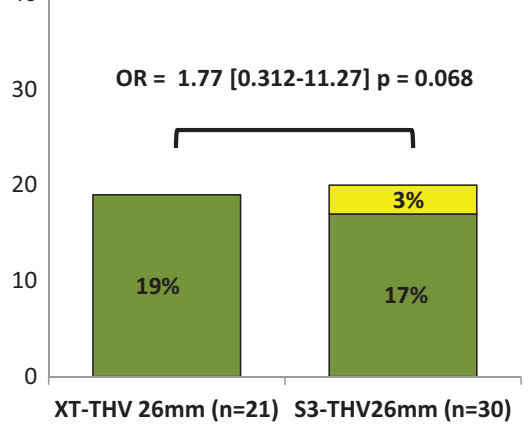

B

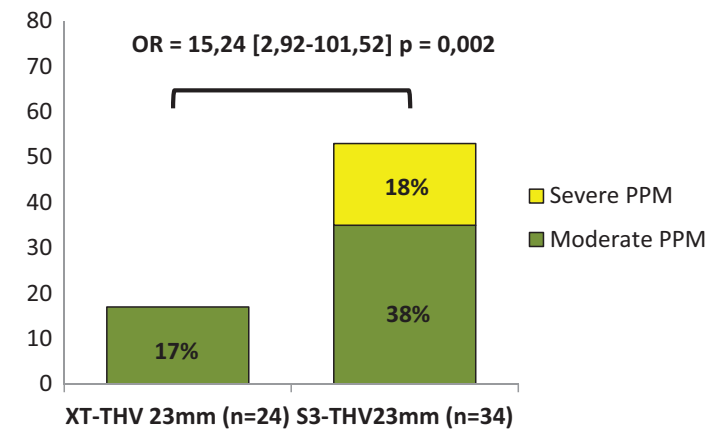

$\square$ Severe PPM

$\square$ Moderate PPM

Figure 3 Incidence of moderate and severe PPM with both prosthesis in overall population (A) and according to prosthesis size: $23 \mathrm{~mm}$ (B), $26 \mathrm{~mm}$ (C).

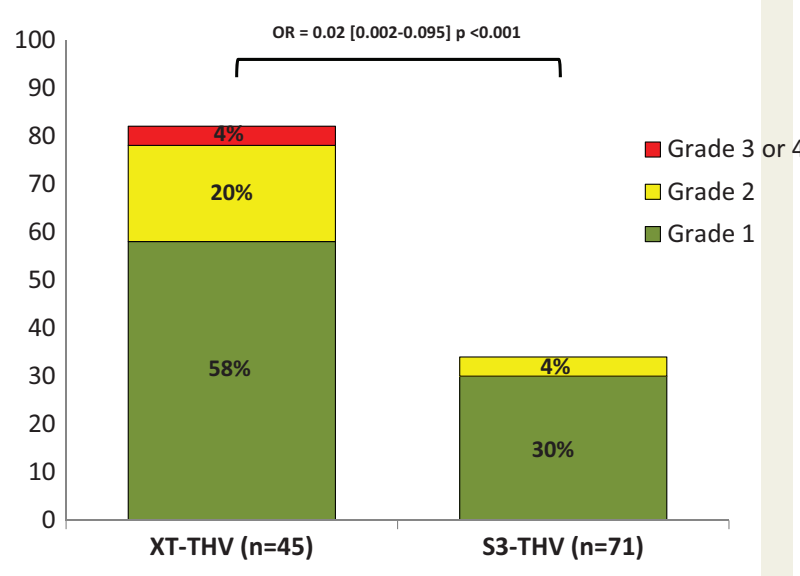

Figure 4 Incidence and severity of PVR according to prosthesis type.

\section{Conclusion}

In this single-centre, retrospective propensity score analysis, we observed an increased risk of PPM only in the smaller size $(=23 \mathrm{~mm})$ S3-THV compared with the former generation of XT-THV but not in the larger sizes where the incidence of PPM remains low. In return, the additional sub-annular cuff of the S3-THV prosthesis significantly reduced the occurrence and severity of PVR. Given the enhanced vulnerability of younger patients to the consequences of PPM, these observations should be useful when considering the extension of the TAVR indication to a younger population.

\section{Supplementary data}

Supplementary data are available at European Heart Journal - Cardiovascular Imaging online.

\section{Conflict of interest: None declared.}

\section{References}

1. Leon MB, Smith CR, Mack M, Miller DC, Moses JW, Svensson LG et al. Transcatheter aortic-valve implantation for aortic stenosis in patients who cannot undergo surgery. N Engl J Med 2010;363:1597-607.

2. Leon MB, Smith CR, Mack MJ, Makkar RR, Svensson LG, Kodali SK et al. Transcatheter or surgical aortic-valve replacement in intermediate-risk patients. N Engl J Med 2016;374:1609-20.

3. Kodali SK, Williams MR, Smith CR, Svensson LG, Webb JG, Makkar RR et al. Two-year outcomes after transcatheter or surgical aortic-valve replacement. $N$ Engl J Med. 2012;366:1686-95.

4. Binder RK, Stortecky S, Heg D, Tueller D, Jeger R, Toggweiler S et al. Procedural results and clinical outcomes of transcatheter aortic valve implantation in Switzerland: an observational cohort study of sapien 3 versus sapien XT transcatheter heart valves. Circ Cardiovasc Interv 2015;8:e002653.

5. Rahimtoola $\mathrm{SH}$. The problem of valve prosthesis-patient mismatch. Circulation 1978;58:20-24. 
6. Pibarot P, Dumesnil JG. Prosthesis-patient mismatch: definition, clinical impact, and prevention. Heart 2006;92:1022-9.

7. Pibarot P, Weissman NJ, Stewart WJ, Hahn RT, Lindman BR, McAndrew T et al. Incidence and sequelae of prosthesis-patient mismatch in transcatheter versus surgical valve replacement in high-risk patients with severe aortic stenosis: a PARTNER trial cohort-a analysis. J Am Coll Cardiol 2014;64:1323-34.

8. Amat-Santos IJ, Dahou A, Webb J, Dvir D, Dumesnil JG, Allende R et al. Comparison of hemodynamic performance of the balloon-expandable SAPIEN 3 versus SAPIEN XT transcatheter valve. Am J Cardiol 2014;114:1075-82.

9. Binder RK, Webb JG, Willson AB, Urena M, Hansson NC, Norgaard BL et al. The impact of integration of a multidetector computed tomography annulus area sizing algorithm on outcomes of transcatheter aortic valve replacement: a prospective, multicenter, controlled trial. J Am Coll Cardiol [Internet]. 2013;62:431-8.

10. Pieter Kappetein A, Head SJ, Généreux P, Piazza N, Van Mieghem NM, Blackstone $\mathrm{EH}$ et al. Updated standardized endpoint definitions for transcatheter aortic valve implantation: The Valve Academic Research Consortium-2 consensus document. Eurolntervention 2012;8:782-795.

11. Clavel M-A, Rodés-Cabau J, Dumont É, Bagur R, Bergeron $S$, De Larochellière $R$ et al. Validation and characterization of transcatheter aortic valve effective orifice area measured by Doppler echocardiography. JACC Cardiovasc Imaging 2014;4:1053-62.

12. Blais C, Dumesnil JG, Baillot R, Simard S, Doyle D, Pibarot P. Impact of valve prosthesis-patient mismatch on short-term mortality after aortic valve replacement. Circulation 2003;108:963-8.

13. Mohty D, Dumesnil JG, Echahidi N, Mathieu P, Dagenais F, Voisine P, Pibarot P. Impact of prosthesis-patient mismatch on long-term survival after aortic valve replacement: influence of age, obesity, and left ventricular dysfunction. J Am Coll Cardiol 2009;53:39-47.

14. Head SJ, Mokhles MM, Osnabrugge RLJ, Pibarot P, Mack MJ, Takkenberg JJM et al. The impact of prosthesis-patient mismatch on long-term survival after aortic valve replacement: a systematic review and meta-analysis of 34 observational studies comprising 27186 patients with 133141 patient-years. Eur Heart J 2012;33:1518-29.

15. Clavel M-A, Webb JG, Pibarot P, Altwegg L, Dumont E, Thompson C et al. Comparison of the hemodynamic performance of percutaneous and surgical bioprostheses for the treatment of severe aortic stenosis. I Am Coll Cardiol [Internet] 2009;53:1883-91.

16. Nijhoff F, Abawi M, Agostoni P, Ramjankhan FZ, Doevendans PA, Stella PR. Transcatheter aortic valve implantation with the new balloon-expandable Sapien 3 versus Sapien XT valve system: a propensity score-matched single-center comparison. Circ Cardiovasc Interv 2015;8:e002408.

17. Binder RK, Rodes-Cabau J, Wood DA, Mok M, Leipsic J, De Larochelliere R et al. Transcatheter aortic valve replacement with the SAPIEN 3: A new balloonexpandable transcatheter heart valve. JACC Cardiovasc Interv 2013;6:293-300.

18. Rodés-Cabau J, Pibarot P, Suri RM, Kodali S, Thourani VH, Szeto WY et al. Impact of aortic annulus size on valve hemodynamics and clinical outcomes after transcatheter and surgical aortic valve replacement: insights from the PARTNER Trial. Circ Cardiovasc Interv 2014;7:701-11.

19. Poulin F, Yingchoncharoen T, Wilson WM, Horlick EM, Généreux P, Tuzcu EM et al. Impact of prosthesis-patient mismatch on left ventricular myocardial mechanics after transcatheter aortic valve replacement. J Am Heart Assoc 2016; 5:e002866.

20. Une D, Mesana L, Chan V, Maklin M, Chan R, Masters RG et al. Clinical impact of changes in left ventricular function after aortic valve replacement: analysis from 3112 patients. Circulation 2015;132:741-7.

21. Weintraub WS, Grau-Sepulveda MV, Weiss JM, O'Brien SM, Peterson ED, Kolm $P$ et al. Appendix-Comparative effectiveness of revascularization strategies. $N$ Engl I Med 2012;366:1467-76.

22. Baumgartner H, Stefenelli T, Niederberger J, Schima H, Maurer G. 'Overestimation' of catheter gradients by Doppler ultrasound in patients with aortic stenosis: a predictable manifestation of pressure recovery. J Am Coll Cardiol 1999;33:1661. 